\title{
Métodos de obtenção de valores de ângulo de atrito e coesão: Comparação entre o ensaio de cisalhamento direto e cálculo baseado no SPT
}

Methods of obtainment of values of internal friction angle and cohesion: comparison between direct shear test and calculation based on SPT

\author{
ANA PAULA DE MELO E SILVA VAZ ${ }^{1}$, ALBERTO PIO FIORI ${ }^{1}$, CLAUDINEI TABORDA DA \\ SILVEIRA $^{1}$
}

${ }^{1}$ Universidade Federal do Paraná - UFPR, Paraná - anapaulamsvaz@gmail.com,fiori@ufpr.br, claudineits@ufpr.br

\begin{abstract}
Resumo
A elaboração de mapas de suscetibilidade é um meio de avaliar previamente áreas que podem sofrer escorregamentos e, para tanto, é necessário conhecer alguns índices físicos do solo como os valores de coesão e o ângulo de atrito. O método mais utilizado para obtenção destes índices físicos é o de cisalhamento direto. Outro método para obtenção de valores de ângulo de atrito e coesão dá-se através de cálculos baseados na resistência do solo à penetração. O presente trabalho utilizou dados obtidos de sondagens Standart Penetration Test (SPT), realizados previamente ao longo da rodovia BR 376 entre os municípios de Curitiba-PR e Garuva-SC, os dados obtidos por meio das sondagens foram base para os cálculos de obtenção dos valores de coesão e ângulo de atrito bem como amostras indeformadas para obtenção dos mesmos parâmetros. Os pontos de coleta de amostra indeformada foram escolhidos próximos aos locais de onde foram realizadas as sondagens, priorizando os mesmos tipos de solo para possibilitar posterior comparação de resultados. Os valores obtidos por meio do cálculo baseado no SPT mostraram-se menores que os valores obtidos por meio do ensaio de cisalhamento direto, o que resultará em mapas de suscetibilidade mais confiáveis.
\end{abstract}

Palavras-chave: Vertentes naturais; Escorregamento; Fator de segurança.

\begin{abstract}
TThe development of susceptibility maps is a way to predict areas that can undergoes landslidings, therefore it is necessary to know some physical indexes such as soil cohesion and angle of internal friction. The most used method to obtain these physical indexes is the direct shear test. There is another method for obtaining the angle of internal friction and cohesion values that is the calculation based on the soil penetration resistance. The present study used data from of Standard Penetration Tests (SPT) previously carried out along BR 376 Road, between the cities of Curitiba-PR and Garuva-SC. The dates was used as base for obtaining cohesion and angle of internal friction values. Undisturbed soil samples were taken close to the SPT points, prioritizing the same types of soil to make possible posterior results comparison. The values obtained by the calculation based on the SPT are lower than the values obtained by the direct shear test, which will result in more reliable susceptibility maps.
\end{abstract}

Keywords: Natural slopes; Landslide; Safety Index

\section{Introdução}

No Brasil é ainda muito incipiente a utilização de estudos para prevenção de processos relacionados aos movimentos de massa. O estudo e análise das condições e das condicionantes que deflagram os deslizamentos é uma ferramenta que pode ser utilizada pelo poder público para prevenção de acidentes e prejuízos, uma vez que a prevenção é economicamente mais viável que a remediação.

Modelos probabilísticos e determinísticos buscam equacionar as variáveis envolvidas nos escorregamentos, sendo o resultado uma previsão de possíveis áreas categorizadas de acordo com a susceptibilidade da área a movimentos de massa, e que são apresentadas em mapas gerados em ambiente de Sistema de Informações Geográficas (SIG).
Um dos problemas que podemos relacionar ao estudo de estabilidade de vertentes é a dificuldade na obtenção de dados significativos, que são fundamentais para que os resultados sejam o mais próximo possível da realidade. A utilização de métodos indiretos diminui custos e facilita tais procedimentos, uma vez que, conhecendo-se como se dá o movimento de massa, pode-se fazer uma análise das variáveis de maior influência.

As propriedades mais significativas dos materiais, na discussão de problemas de estabilidade, são o ângulo de atrito e a coesão de solos e rochas (GUIDICINI \& NIBLE, 1983).

As propriedades físicas podem ser então aplicadas a fórmulas que resultaram em índices de segurança para as vertentes estudadas. 
Apesar de o ensaio de cisalhamento direto ser simples de ser realizado, Braja (2013) destaca que o mesmo possui algumas deficiências inerentes ao processo, como fato de que a confiabilidade dos resultados pode ser questionada, uma vez que o ensaio induz o rompimento da amostra ao longo do plano de separação das caixas de cisalhamento e não no plano mais fraco.

O presente trabalho tem como objetivo comparar dois métodos utilizados para a obtenção de valores de ângulo de atrito e coesão por meio do ensaio de cisalhamento direto e pelo cálculo baseado na resistência do solo à penetração, obtido por meio de Standart Penetration Test (SPT), e com isso determinar se aplicação do cálculo pode ser utilizado como meio indireto para obtenção destes índices físicos do solo. E, finalmente, através de técnicas de sistemas de informação geográfica, realizar a espacialização dos resultados das equações do Fator de Segurança (FS) da área de estudo, conforme Silveira et. al., (2012), sendo que os cálculos dos FS foram baseados na proposta apresentada por Fiori e Carmgnani (2009).

\section{Comparação entre os métodos}

Para a elaboração do presente estudo foram utilizados relatórios de sondagem fornecidos pela concessionária OHL, que administra a rodovia BR 376, além de cartas topográficas em curvas de nível equidistantes 10 metros. Os trabalhos de campo foram realizados entre os meses de outubro, novembro e dezembro de 2013. O trecho objeto de estudo vai do $\mathrm{km} 667$ ao km 668.

Buscou-se a caracterização dos tipos de solo quanto a sua formação e rocha de origem, buscando uma melhor compreensão das suas propriedades geológicogeotécnicas e, consequentemente, das condições de estabilidades das vertentes que compõe a região de estudo, além da validação do mapa de solos.

O SPT é reconhecidamente a mais popular, rotineira e econômica ferramenta de investigação em praticamente todo o mundo, permitindo uma indicação da densidade de solos granulares, também aplicado à identificação da consistência de solos coesivos e mesmo de rochas brandas (SCHNAID, 2000).

$\mathrm{O}$ ensaio de SPT, como um ensaio de penetração dinâmica, de acordo com Cintra et. al. (2013), consiste de três etapas: I) perfuração; II) amostragem; e III) ensaio penetrométrico. As etapas II e III são simultâneas, enquanto a etapa I é alternada com as etapas II/III a cada metro da sondagem.

De acordo com os estudos de Pinto (2000), a resistência à penetração é também conhecida como o número NSPT, ou simplesmente, como SPT do solo. Os solos podem então ser classificados através da compacidade, quando se tratar de areia ou de silte argiloso, ou pela consistência, para o caso das argilas ou de silte argiloso. Esta classificação dá-se em relação à resistência à penetração.

Devido à disponibilidade de dados relativos a sondagens realizadas na área de estudo, os valores de resistência à penetração foram utilizados para obtenção de valores de ângulo de atrito e coesão, em função da profundidade e NSPT.

A correção do NSPT foi realizada quanto à eficiência e à tensão confinante para uma tensão de referência de $100 \mathrm{kPa}(\mathrm{N} 1)$. Para tanto, foi necessário determinar a tensão vertical efetiva ( $\left.\delta v^{\prime}\right)$ e o coeficiente de correção (CN) através das equações 1, 2 e 3 descritas por Liao e Withman (1986).

$$
\sigma_{v}^{\prime}=z \times \gamma_{\text {nat }} \text { (Equação 1) }
$$

Onde:

$\sigma v^{\prime}$ - tensão vertical efetiva;

$\mathrm{Z}$ - altura ou profundidade;

Xnat - peso específico do solo natural.

$$
C N=\sqrt{\frac{100}{\sigma^{\prime}{ }_{v}}}(\text { Equação 2) }
$$

Onde:

$\mathrm{CN}$ - coeficiente de correção;

$\sigma v^{\prime}-$ tensão vertical efetiva.

$$
\begin{aligned}
& N_{1}=N_{S P T} \times C N \text { (Equação 3) } \\
& \text { Onde: } \\
& \mathrm{N} 1 \text { - valor do Nspt corrigido; } \\
& \mathrm{Nspt} \text { - número de golpes; } \\
& \mathrm{CN} \text { - coeficiente de correção. }
\end{aligned}
$$

Para correção do NSPT para um valor de referência, normalizado com base no padrão americano de N60, onde a energia liberada é de $60 \%$, e o valor utilizado como energia aplicada é de 0,66, conforme indicado por Schnaid (2000). A Equação (4) demonstra o cálculo da correção.

$$
N_{60}=\frac{N_{S P T} \times \text { Energia aplicada }}{0,60}(\text { Equação 4) }
$$

Uma correlação direta com o NSPT corrigido em relação à energia aplicada ao sistema e ao nível de tensões (N1)60, para o caso de materiais granulares foi proposta por Hatanaka e Uchida (1996), conforme mostra a Equação 5.

$$
\varphi=20+\left(15,4 \times(N 1)_{60}\right)^{1 / 2}(\text { Equação 5) }
$$

Já para o caso de materiais coesivos, de acordo com Stroud, (1989) o parâmetro a ser determinado e a resistência não-drenada $(\mathrm{Su})$, como apresentado na Equação 6.

$$
S_{u}=5 \times N_{60}(k P a) \text { (Equação 6) }
$$

Para encontrarmos a coesão e o ângulo de atrito, utilizou-se a Equação (7).

$$
\tau=\sigma_{v}^{\prime} \times \tan \varphi_{(N 1) 60} \quad \text { (Equação 7) }
$$


Caso a suposição seja para um material coesivofriccional, com o valor da resistência ao cisalhamento é possível obter o valor da coesão (c') utilizando-se um valor fixo para $\phi$ (Equação 8).

$$
c^{\prime}=\tau-\sigma_{v o}{ }^{\prime} \times \tan \varphi(\text { Equação } 8)
$$

Esses cálculos foram realizados em todos os 37 pontos de sondagem abordadas na presente pesquisa, o que resultou em uma tabela para cada ponto de sondagem. Como resultado, obtiveram-se 37 tabelas e devido ao grande volume de informação contida nas tabelas de cálculo está apresentado resumidamente no decorrer do texto.

\section{Amostragem e caracterização dos solos}

A coleta de amostra indeformada foi realizada conforme recomenda a norma NBR 9604/1986 (ABNT, 1986).

A profundidade da base dos blocos variou entre $1 \mathrm{e}$ 1,5 metros, variações necessárias para que as amostras ficassem, o máximo possível, livres de raízes e pedregulhos e, portanto, o nível superior de amostragem mostrou-se após a retirada do solo orgânico

Ao longo da rodovia, observaram-se três tipos principais de solo: residuais, coluvionares e tálus. Um tipo particular de solo residual estratificado foi observado no km 682.

De um modo geral, os solos residuais são de cores amareladas ou avermelhadas, bastante argilosos, frequentemente evidenciando estruturas reliquiares da rocha matriz. Em relação à rocha matriz, observaramse dois tipos principais: solos residuais de migmatitos e solos residuais de granito.

Os solos residuais de migmatitos são os mais abundantes e caracterizam-se pela predominância das cores amareladas, e são bastante argilosos e compactos. Nesse tipo de solo, é frequente a presença de estruturas reliquiares da rocha matriz, caracterizada por níveis de colorações esbranquiçadas devido à maior concentração de minerais félsicos como feldspatos e quartzo. Além disso, ocorrem níveis mais marrons/avermelhados devido à maior concentração de óxidos e hidróxidos de ferro, provenientes da decomposição de minerais máficos como biotita e anfibólios. A granulometria dos minerais reliquiares é de média a grossa.

Os solos residuais de granito caracterizam-se por cores mais avermelhadas e, a exemplo dos solos residuais de migmatitos, são também bastante argilosos e compactos. Diferenciam-se dos primeiros, tanto pela cor mais avermelhada, como pela ausência de estruturas reliquiares na forma de níveis de cores diferentes da rocha matriz. A estrutura reliquiar observada nesse tipo de solo é caracterizada por um aspecto granulométrico, dado pela alteração intempérica de feldspatos, produzindo cores claras e de minerais máficos, que resultam em cores avermelhadas. A granulometria dos minerais reliquiares é grossa. Bons exemplares desse tipo de solo podem ser observadas no trecho da rodovia entre os km 659 e km 667, sentido Curitiba/PR-Garuva/SC.

Os solos identificados como depósitos de tálus caracterizam-se pela presença de blocos de rocha, geralmente granitos e migmatitos, de tamanhos e formas muito diversificadas, imersos em uma matriz argilo-arenosa. É comum nesse tipo de solo a presença de matacões de rochas, bem como outros blocos e fragmentos menores, geralmente quartzosos, de alguns centímetros de comprimento. Há, no entanto, toda uma gradação de tamanhos de fragmentos rochosos dentro dos depósitos de tálus. Uma boa ocorrência desse tipo de solo pode ser observada no Km 669.

Os solos coluvionares caracterizam-se pelas cores marrom avermelhado ou marrom amarelado, tipo tijolo, de matriz argilo-arenosa e sem evidências de estruturas reliquiares da rocha matriz. Ocorrem sobre solos residuais, sendo, em alguns casos, bem marcada a transição entre ambos, especialmente por uma brusca mudança de coloração. Localizam-se principalmente nos topos mais aplainados ou nas porções inferiores das vertentes. Aparentemente, a espessura desse tipo de solo é bastante irregular.

A partir dos dados de sondagem fornecidos pela Concessionária OHL, foram utilizadas apenas as informações relevantes que apresentassem coordenadas geográficas, de modo que os pontos de sondagem pudessem ser plotados nos mapas.

Toda informação obtida por meio dos boletins de sondagem foi organizada para que, posteriormente, se pudessem realizar os cálculos para obtenção dos valores referentes a ângulo de atrito e coesão do solo.

A primeira etapa de análise de resultados da presente pesquisa baseou-se na delimitação da área de estudo, da qual foram selecionadas sete unidades amostrais. Optou-se por classificar as sondagens em unidades amostrais, identificadas e agrupadas de acordo com o $\mathrm{km}$ da rodovia. Como todos os locais escolhidos possuem mais de um ponto de sondagem e o resultado apresentado é dado pela média da coesão e do ângulo de atrito do local e não somente de um único furo de sondagem. Ao todo foram avaliados 37 pontos de sondagem SPT para obtenção de valores de ângulo de atrito e coesão por meio da correlação com o NSPT.

$\mathrm{Na}$ segunda campanha de campo, foram confirmados os pontos de coleta determinados na primeira campanha realizada anteriormente. Alguns pontos foram realocados, sendo eleitos quinze pontos de coleta de amostras indeformadas, dos quais, quatro deles estão na área de estudo.

Após a coleta, as amostras foram transportadas para o Laboratório de Materiais e Estruturas (LAME) do Departamento de Construção Civil, da Universidade Federal do Paraná. Em nenhum dos locais de coleta foi observado instabilidade das paredes durante a escavação. A localização e o tipo de solo dos locais de coleta estão dispostos na Tabela 1. 
Tabela 1 - Localização e caracterização dos pontos de coleta de amostra indeformada.
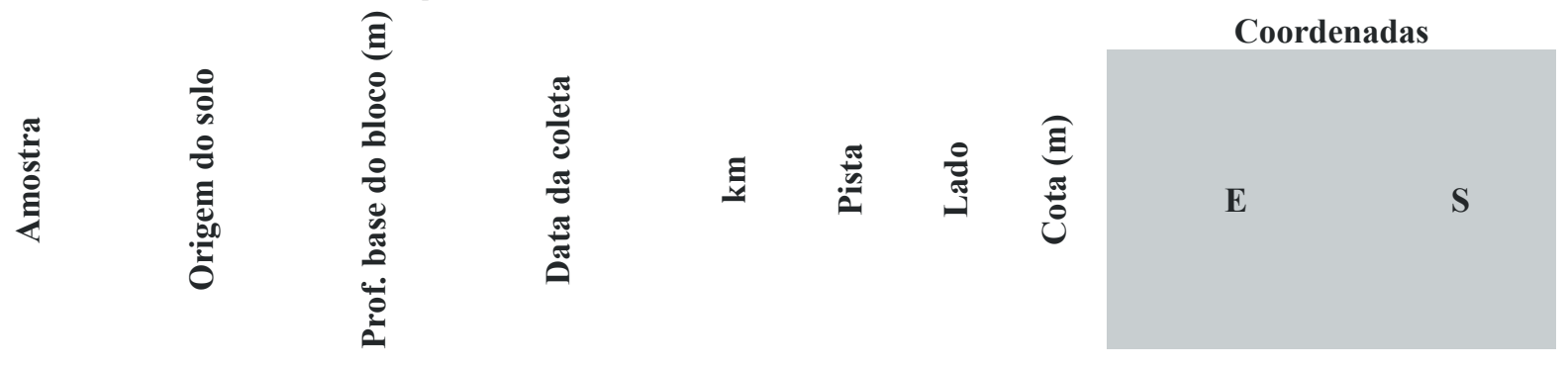
AI- Aterro
1,40
$19 / 11 / 2013$

1,20

$18 / 11 / 2013$

669

$\mathrm{N}$

LD

507

0706896

7136787

$\begin{array}{lllllllll}\text { AI-13 Colúvio } & 1,50 & 19 / 11 / 2013 & 668 & \mathrm{~N} & \mathrm{LD} & 582 & 0706740 & 7138096\end{array}$

\begin{tabular}{|c|c|c|c|c|c|c|c|c|c|}
\hline $\begin{array}{l}\text { AI- } \\
13 A\end{array}$ & $\begin{array}{l}\text { Residual } \\
\text { Migmatito }\end{array}$ & 1,00 & $19 / 11 / 2013$ & 668 & $\mathrm{~N}$ & LD & 601 & 0706721 & 7138133 \\
\hline AI-14 & $\begin{array}{l}\text { Residual } \\
\text { Granito }\end{array}$ & 1,30 & $20 / 11 / 2013$ & 667 & $\mathrm{~N}$ & LD & 618 & 0706474 & 7138248 \\
\hline
\end{tabular}

Após as coletas das amostras indeformadas, os blocos foram protegidos por tecido e parafina para evitar a perda da umidade natural e armazenados na câmara úmida até a moldagem dos corpos de prova, feita em anéis metálicos quadrados com medida de lado aproximada de $100 \mathrm{~mm}$ e altura média aproximada de $20 \mathrm{~mm}$.

Após a moldagem, os corpos-de-prova foram retificados para igualar a altura de solo à altura do anel. Os corpos de prova que não foram transferidos para a

Tabela 2 - Amostras, tipo de ensaio, tensões e carregamento.
Ensaio

AI-05A
AI-12
AI-13 $\quad$ Cisalhamento direto
AI-13A
AI-14

O adensamento foi realizado durante mais de doze horas. E durante -esta etapa, o equipamento fez as devidas leituras do deslocamento vertical devido ao carregamento.

A segunda etapa do ensaio é o cisalhamento, que consiste no início das leituras de deslocamento horizontal, e foi realizado em todas as amostras à velocidade de $0,007 \mathrm{~mm} / \mathrm{min}$. Esta etapa do ensaio durou, em geral, cerca de 6 horas, e a leitura do deslocamento horizontal foi realizada a cada minuto. $\mathrm{O}$ caixa de cisalhamento para ensaio foram embalados em papel filme para que se reduzisse a perda da umidade natural.

Então procedeu-se o adensamento, a amostra foi colocada no aparelho onde realizou-se o cisalhamento após $\mathrm{o}$ adensamento. $\mathrm{O}$ carregamento para $\mathrm{o}$ adensamento foi feito através da colocação de pesos relativos às tensões que serão utilizadas no ensaio, tensões essas dispostas na Tabela 2. 
amostras indeformadas, pois nem todos os boletins de sondagem apresentaram coordenadas. Por este motivo, foram utilizadas somente as unidades amostrais nomeadas entre o $\mathrm{km} 667$ e o $\mathrm{km} 668$.

Então, os pontos de coleta de amostra indeformada e as unidades amostrais mais próximas que apresentaram o mesmo tipo de solo, foram selecionados para comparação de resultados. Como os resultados do

Tabela 3 - Comparação de valores: calculados por SPT; ensaio de cisalhamento direto. cálculo baseado no SPT são obtidos com base na profundidade, os valores selecionados levaram em consideração a cota da coleta do bloco de solo. Da mesma maneira foram selecionados os valores obtidos para ângulo de atrito e coesão.

A Tabela 3 apresenta valores de ângulo de atrito e coesão das amostras indeformadas.

Área de estudo

\begin{tabular}{|c|c|c|c|c|c|c|c|}
\hline 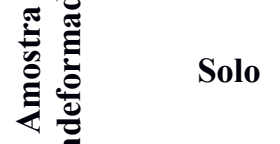 & $\begin{array}{c}\text { Prof. } \\
\text { (m) }\end{array}$ & $\begin{array}{l}\Phi \\
\left({ }^{\circ}\right)\end{array}$ & $\begin{array}{c}\mathrm{C} \\
(\mathrm{kPa})\end{array}$ & $\begin{array}{c}\text { Unidade } \\
\text { amostral } \\
\text { SPT }\end{array}$ & Solo & $\begin{array}{c}\text { Prof. } \\
\text { média } \\
\text { (m) }\end{array}$ & $\begin{array}{c}\text { Média } \\
\text { do } \Phi\left({ }^{\circ}\right)\end{array}$ \\
\hline
\end{tabular}

\begin{tabular}{llllllllll}
\hline AI-05A & Aterro & 1,4 & 37,77 & 3,87 & $667+710$ & $\begin{array}{l}\text { Aterro/ } \\
\text { coluvio }\end{array}$ & 2 & 32,39 & 9,81
\end{tabular}

AI-12 Aterro $\quad 1,2 \quad 32,4 \quad 6,42$ Não houve coleta de amostra indeformada na proximidade

\begin{tabular}{cccccccccc} 
AI-13 & Coluvio & 1,5 & 34,14 & 3,07 & $667+120$ & Coluvio & 1,76 & 31,69 & 3,22 \\
AI-13A & $\begin{array}{c}\text { Residual de } \\
\text { migmatito }\end{array}$ & 1,5 & 37 & 2,9 & $667+900$ & $\begin{array}{c}\text { Solo } \\
\text { residual }\end{array}$ & 2,1 & 30,61 & 4,52 \\
\hline AI-14 & $\begin{array}{c}\text { Residual de } \\
\text { granito }\end{array}$ & 1,0 & 28,9 & 14,6 & $667+160$ & $\begin{array}{c}\text { Solo } \\
\text { residual }\end{array}$ & 1,26 & 31,09 & 2,87 \\
\hline
\end{tabular}

Percebe-se que os valores obtidos para ângulo de atrito obtidos por meio do cálculo são pouco menores que os valores que resultaram do ensaio de cisalhamento direto, o que segundo Fiori (op. cit.), influência nos cálculos do fator de segurança de maneira positiva, uma vez que quanto menor for o ângulo de atrito maior será a margem de segurança obtida através do cálculo do FS. Com base nos valores apresentados na Tabela 23, o valor médio para ângulo de atrito obtido por meio do cisalhamento direto é de $34,02^{\circ}$ e o valor médio obtido pelo cálculo baseado no SPT é de $31,44^{\circ}$.

Com relação à coesão, tanto no presente estudo quanto nas pesquisas de Borchardt (2005) e Kozciak (2005), os valores apresentaram variação, tanto para o valor calculado quanto para o obtido no ensaio de cisalhamento direto. No caso da presente pesquisa, o valor médio da coesão obtido pelo cálculo baseado no SPT é de $5,1 \mathrm{kPa}$ e o valor médio resultante do cisalhamento direto é de $6,17 \mathrm{kPa}$.

Para materiais amostrados em Cubatão, SP, Ferreira (2013) também obteve os valores de ângulo de atrito e coesão por meio de ensaio de cisalhamento direto. Os solos estudados pelo referido autor foram classificados pelas texturas franco arenoso, franco argiloso e franco siltoso. Os valores de ângulo de atrito variaram entre $29,1^{\circ}$ a $36.7^{\circ}$, sendo tais valores muito próximos aos encontrados na presente pesquisa. O mesmo acontece com os valores referentes à coesão, para os quais a autora encontrou valores entre 0 e $11,05 \mathrm{kPa}$. Nesse caso, a diferença com a presente pesquisa é que o menor valor encontrado para coesão foi de $2,87 \mathrm{kPa}, \mathrm{o}$ que pode indicar que os solos estudados não possuem percentual de areia tão grande quanto o estudado em Cubatão.

Ainda com relação ao trabalho de Ferreira (2013), são citados valores dos trabalhos de autores que realizaram suas pesquisas em 1994, nas quais, Wolle e Carvalho (1989) encontraram valores muito próximos para solos areno-argilosos e arenosos, sendo o ângulo de atrito, das camadas superficiais menor que $34^{\circ}$, tendo a coesão variado entre 1 e $4 \mathrm{kPa}$.

Outro trabalho que pode ser acrescentado a discussão é o de Amaral Junior (2007), no qual os valores obtidos para coesão variaram de 1 a $9 \mathrm{kPa}$, e o ângulo de atrito de variou de 32 a $42^{\circ}$. 
Pode-se que dizer os dados apresentados tanto na pesquisa de Ferreira (2013), tanto quanto os das demais referências por ela utilizados estão muito próximos dos valores encontrados na presente pesquisa, a não ser pelo valor mais alto para ângulo de atrito, de $45^{\circ}$, que encontrou Amaral Junior (2007).

Em um trabalho de modelagem para gestão de áreas susceptíveis a escorregamentos, elaborado para a região de Vitória, ES, Silva et. al. (2013) utilizou uma faixa de valores para ângulo de atrito e coesão para obtenção de mapas em diversos cenários. Para isso, utilizaram os seguintes valores: ângulo de atrito $25^{\circ}$, $30^{\circ}, 35^{\circ}, 40^{\circ}$ e $45^{\circ}$; e coesão $0,2,4,6$ e $8 \mathrm{kPa}$. Tanto por meio do cálculo por SPT, quanto pelo ensaio de cisalhamento direto realizado para a área de estudo da presente pesquisa, os valores estão dentro da mesma faixa.

Como os escorregamentos de massa são condicionados ao tipo de solo onde ocorrem, antes da obtenção do mapa de FS, para tanto, foi necessário gerar um mapa previsional de solos que, posteriormente, foi validado com observações no sítio de estudo.

Para obter o mapa previsional de solos, a modelagem dos tipos de solos superficiais foi dividida em três etapas principais: a) elaboração dos atributos topográficos e geração de um mapa previsional de solos de toda a área; b) validação do mapeamento em campo; e c) etapas de classificação, validação e correção de dados espúrios.

Os mapas planialtimétricos elaborados pelo Programa de Proteção da Floresta Atlântica - Paraná (PRÓ-ATLÂNTICA) do Instituto de Terras, Cartografia e Geociências (ITCG), em escala 1:25.000, foram usados como base para análise do terreno e modelagem do mapa previsional de solos.

No ambiente do software de informações geográficas, ArcGis versão 10.1 (ESRI, 2011), processou-se o MDT em grade regular com algoritmo ANUDEM (Topo to Raster). Sendo que o processo de geração de grade regular consiste em estimativa dos valores de cota de cada ponto de grade a partir de um conjunto de amostras de entrada, que podem ser espaçadas regular ou irregularmente. Este método difere-se de outros métodos de interpolação por gerar modelos hidrologicamente corretos e com grade regular que possibilita a estimativa de inúmeras variáveis do terreno. A resolução espacial do pixel no arquivo de saída ficou definida em $10 \mathrm{~m}$ x $10 \mathrm{~m}$.

A partir da construção dos modelos, foi possível realizar o processamento dos atributos topográficos que serviram como base para elaboração do mapa preliminar de solos. Foram utilizados como atributos topográficos:

a) Índice de Posição Topográfica (IPT) que mede a elevação de um ponto central e a média da elevação ao seu redor, em um raio predeterminado. Valores positivos representam posições mais elevadas, e os valores negativos representam os locais mais baixos, como o terço inferior das vertentes, ou seja, solos de origem coluvionar. Como este índice pode ser afetado pela escala, foi utilizado como medida interna 10 pixels e externa de 13 pixels. Após a aplicação de filtro, agrupamentos com menos de nove células foram eliminados. A delimitação entre os tipos de solo foi obtida pela média dos dados obtidos pelo IPT, que se adequaram às curvas de nível de maneira fidedigna;

b) Índice topográfico de umidade (ITU): usado para caracterização da distribuição espacial de zonas de saturação superficial. Este prevê a saturação onde a área de contribuição é grande, geralmente em segmentos convergentes, predominantemente na base de vertentes côncavas. O ITU associa-se também ao caminho preferencial da água, devido aos gradientes de umidade no perfil do solo. Após a discretização dos dados, realizada a partir da análise do histograma de distribuição dos valores de cada pixel, foram considerados como classes com alta concentração de umidade os pixels com valores superiores a 15 , o que indica ambientes com processos aluvionares.

Com base no modelo de ocorrência, apoiado no IPT, foi possível indicar a distribuição dos solos residuais e coluvionares. Por sua vez, o ITU foi utilizado para a detecção das áreas nas quais as ocorrências aluvionares superam as coluvionares. Finalmente, a partir do mapa geológico, os solos residuais foram organizados em 3 classes distintas: 1) Solos residuais gnáissicos-migmatitícos; 2) solos residuais graníticosgnáissicos e 30 solos residuais de outros litotipos. No mapa, são indicadas as áreas de afloramento rochoso, identificadas por imagens de satélite de alta resolução e ortofotos.

A etapa de campo buscou a caracterização dos tipos de solo quanto a sua formação e à rocha de origem, a fim de melhor compreender suas propriedades geológico-geotécnicas e, consequentemente, das condições de estabilidades das vertentes que compõe a região de estudo. Foi uma importante etapa para validar o mapa de solos, que é apresentado na Figura 1.

A fim de comparar a estabilidade das vertentes em condições diferentes de equilíbrio, calcula-se o Fator de Segurança (FS).

O fator de segurança é a razão entre as forças resistentes ao deslizamento e a resultante das forças solicitantes. A condição especial de equilíbrio-limite corresponde a um FS de valor igual a 1,00, e nesse caso, o escorregamento é iminente. Quanto maior for o valor acima da unidade, maior a estabilidade da vertente e, por consequência, menor a susceptibilidade de ocorrência desse processo (SILVEIRA et. al., 2012).

$\mathrm{O}$ fator de segurança, de acordo com Fiori e Carmignani (2009), é influenciado por diversos fatores. O presente estudo baseou-se na teoria do equilíbrio limite em taludes infinitos, conforme descrito pelos autores. 
A análise baseada na teoria de equilíbrio limite considera que as forças que tendem a induzir a ruptura são exatamente equilibradas pelos esforços resistentes, conforme mostra a Equação 9.

$$
F_{S}=\frac{\text { Forças resistentes }}{\text { Forças atenuantes }} \text { Equação (9) }
$$

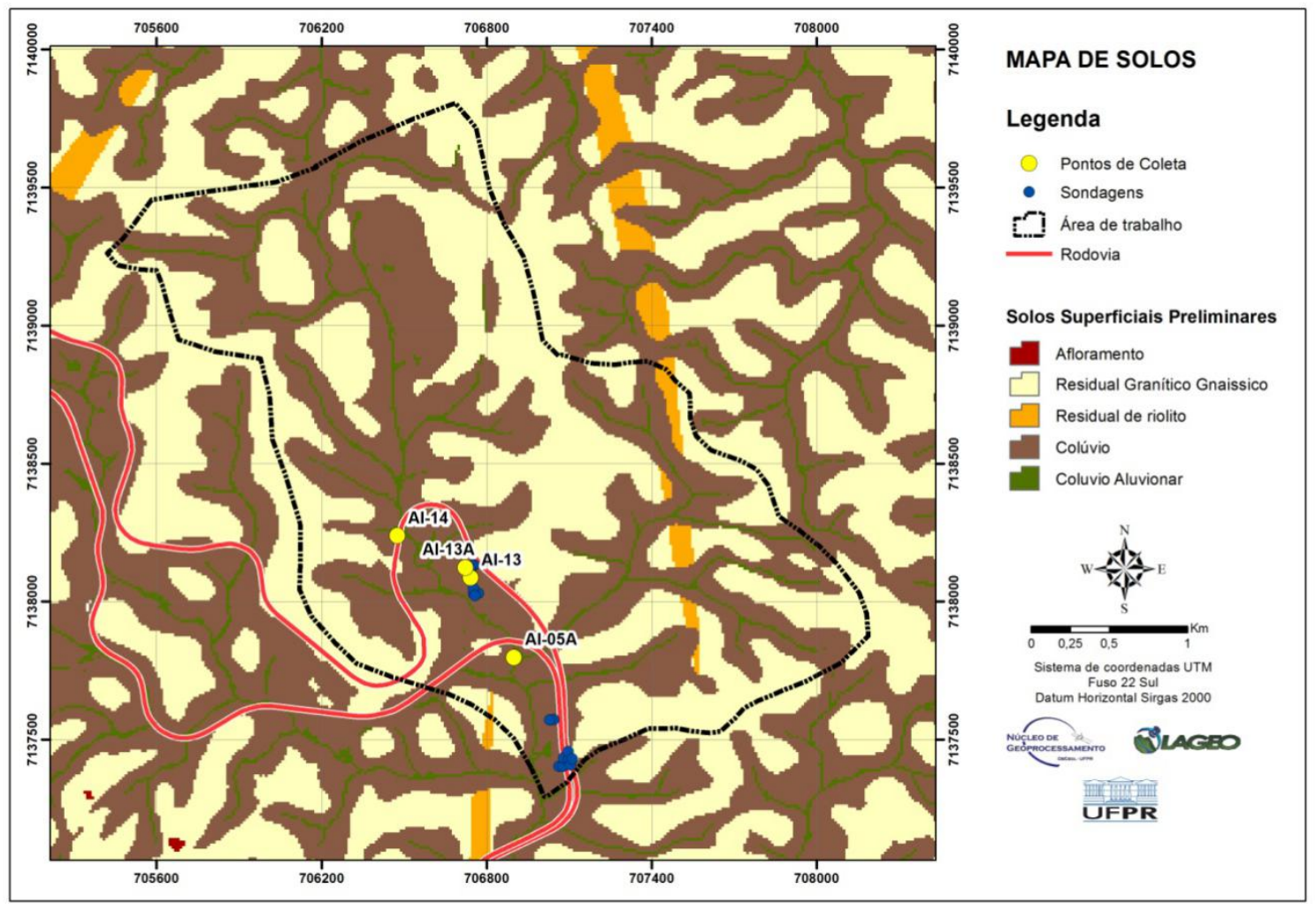

Figura 1 - Mapa de solos.

Para obtenção valor do Fator de Segurança, foi utilizada a equação, descrita por Fiori e Carmignani (2009), para taludes infinitos, que leva em consideração a influência da vegetação, conforme Equação 10.

$F S=\frac{\left(C_{s}+S_{r}\right)\left[\left(h_{1} \gamma_{n a t}+h_{2} \gamma_{i}+P_{a}\right) \cos ^{2} i+\operatorname{sen} \theta\right] \operatorname{tg} \varphi+T \cos \theta}{\left[\left(h_{1} \gamma_{n a t}+h_{2} \gamma_{i}+h_{2} \gamma_{a}+P_{a}\right) \operatorname{sen} i+F_{v e}\right] \cos i}$

(Equação10)

Onde:

FS - Fator de segurança (adimensional);

$\mathrm{Cs}$ - Coesão do solo $(\mathrm{kPa})$;

$\mathrm{Sr}$ - Contribuição das raízes para coesão total do solo $(\mathrm{kPa})$;

$\mathrm{h}$ - Altura da zona de solo, perpendicular a vertente (m);

Xa - Peso específico da água $(\mathrm{kN} / \mathrm{m} 3)$;

$\mathrm{Pa}$ - Peso das árvores $(\mathrm{kPa})$;

i - Inclinação da vertente (graus);

$\mathrm{T}$ - Tensão das raízes $(\mathrm{kPa})$;

Fve - Força do vento $(\mathrm{kPa})$

Vários autores utilizam a Equação 10 de diversas maneiras, considerando-se que, para obter distintos cenários, é preciso apenas determinar-se qual será a variável que sofrerá modificação para obter resultados diferentes.

Desta maneira, é possível modificar praticamente todos os valores utilizados no cálculo para se ter como resultado um cenário específico que representará as condições de contorno de um possível evento.

Para a elaboração do mapa, utilizaram-se técnicas que contemplam o uso de SIG, descritas por Silveira et. al. (2012). O cálculo do FS baseou-se na proposta apresentada por Fiori e Carmignani (2009).

Como os valores encontrados pela relação feita com os valores do SPT para ângulo de atrito e coesão foram menores do que os determinados por cisalhamento direto (TABELA 3), optou-se pela utilização dos obtidos por meio do SPT, com isso tem-se uma margem ainda mais segura para o FS encontrado, porém outros dados são necessários logo, os valores utilizados referentes ao peso específico do solo natural reportam-se às pesquisas de Borchardt (2005) e Kozciak (2005), os valores utilizados no presente estudo para calcular o Fs estão apresentados na Tabela 4. 
Tabela 4 - Valores utilizados para obtenção do Mapa do Fator de Segurança. *Valores apresentados por Borchardt (2005) e Kozciak (2005).

\begin{tabular}{lccccc}
\multicolumn{1}{c}{ Tipo de solo } & $\begin{array}{c}\text { Ângulo de } \\
\text { atrito }\left(^{(}\right)\end{array}$ & $\begin{array}{c}\text { Coesão } \\
\left(\mathbf{c}^{\prime}\right)\end{array}$ & $\begin{array}{c}\text { Gama } \\
\text { nat } \\
(\mathbf{X n a t})\end{array}$ & $\begin{array}{c}\text { Espessura } \\
(\mathbf{m})\end{array}$ & $\begin{array}{c}\text { Localização: km / amostra } \\
\text { indeformada }\end{array}$ \\
$\begin{array}{l}\text { Residual granito- } \\
\text { gnáissico }\end{array}$ & 31,09 & 2,87 & 18 & 16 & $\mathrm{Km} 667+160 / \mathrm{AI}-14$ \\
\hline $\begin{array}{l}\text { Residual (migmatito) } \\
\text { Colúvio }\end{array}$ & 30,61 & 4,52 & 18 & 17,57 & $\mathrm{Km} 667+900 / \mathrm{AI} 13 \mathrm{~A}$ \\
\hline
\end{tabular}

Então, com base no mapa de solos e nos valores de ângulo de atrito, coesão (c'), peso específico do solo natural ( $\gamma$ nat), e espessura $(\mathrm{m})$, estes dados foram combinados no software ArcGis ${ }^{\circledR}$ versão 10.1 (ESRI, 2011), foi possível obter o mapa do FS.

Para o cálculo do FS, os valores apresentados na Tabela 4 foram extrapolados para toda área da subbacia respeitando-se a distribuição dos tipos de solos, então com base no mapa de solos e do equacionamento dos dados apresentados, foram então aplicados na Equação 10 para determinação do FS no ambiente do software ArcGis ${ }^{\circledR}$, tendo como resultado um mapa preliminar de susceptibilidade ao escorregamento.

$\mathrm{O}$ resultado obtido pela aplicação da equação do FS de segurança é qualitativo e, neste caso, foi divido em quatro classes, sendo que as áreas de muito alta susceptibilidade a escorregamentos correspondem a FS $<$ 1,25. A área classificada como de alta susceptibilidade apresenta valores entre 1,25 e 1,5; a classe moderada susceptibilidade compreende valores $1,5<\mathrm{FS}<2,0$; e, para as áreas de baixa susceptibilidade, FS $>2,0$, como mostra a Figura 2.

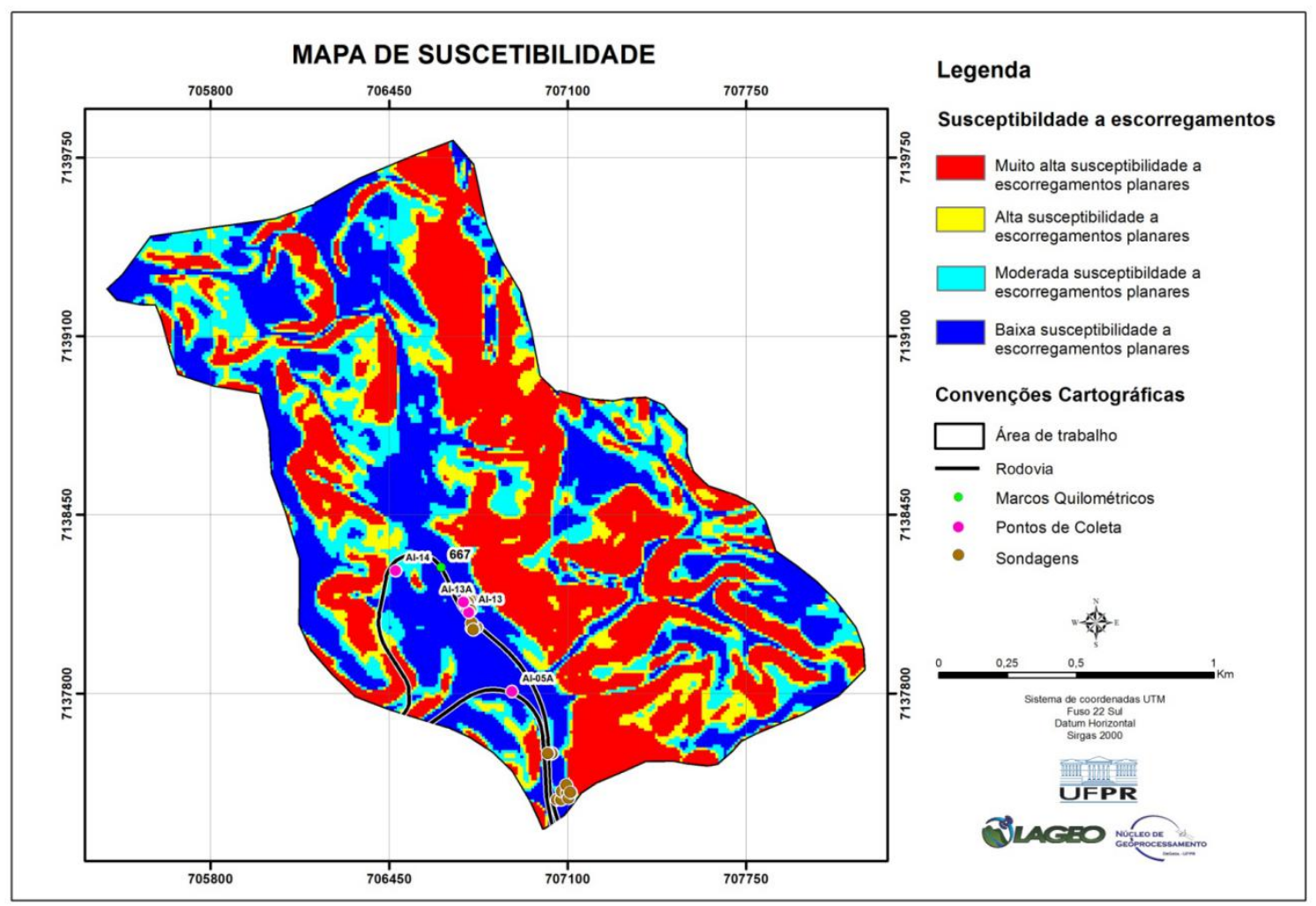

Figura 2 - Mapa de susceptibilidade a escorregamentos da sub-bacia estudada.

Neste último mapa pode-se perceber que a maior parte da área, principalmente a aquela localizada ao norte da rodovia, foi classificada com área de muito alta susceptibilidade aos escorregamentos.
O mapa expressa a espacialização dos valores obtidos na fórmula do FS e depois são diretamente relacionados a valores qualitativos, pois apontam o grau de segurança quanto a escorregamentos de cada área representada. 
Para melhor visualização dos percentuais de cada categoria de susceptibilidade, os valores do FS estão

dispostos na Tabela 5 .

Tabela 5 - Área e percentual de classes de susceptibilidade a escorregamento.

\begin{tabular}{|c|c|c|c|}
\hline Classes de suscetibilidade & Valor & Área $\left(\mathrm{m}^{2}\right)$ & Percentual (\%) \\
\hline Muito alta suscetibilidade & $<1,25$ & 1.189 .700 & 36,7 \\
\hline Alta suscetibilidade & $1,25-1,50$ & 452.300 & 14,0 \\
\hline Moderada suscetibilidade & $1,5-2,00$ & 595.300 & 18,4 \\
\hline Baixa suscetibilidade & $>2,00$ & 1.000 .800 & 30,9 \\
\hline Área total & & 3.238 .100 & \\
\hline
\end{tabular}

Com base no exposto na Tabela 5 , da área total de estudo, $50,7 \%$ da área estudada foi classificada como muito alta e alta susceptibilidade, sendo que a maior concentração desta classe está ao norte da rodovia (Figura 28). Com base nestas informações, é possível perceber que a área da sub-bacia, convergente à rodovia, influencia diretamente na segurança da mesma. Os registros de escorregamentos e obras, realizados pela concessionária que administra a rodovia, confirmam que aquela é uma área bastante problemática.

\section{Conclusões}

A pesquisa bibliográfica realizada para este trabalho mostrou uma lacuna científica com relação à obtenção de valores de ângulo de atrito e coesão através dos cálculos baseados em sondagens SPT em áreas similares, além de não ter sido possível identificar comparações de valores obtidos por esta metodologia e por ensaio de cisalhamento direto.

A obtenção dos diversos mapas previsional de solos e de susceptibilidade a escorregamentos, apresentados no presente trabalho, possibilitou uma caracterização da área tanto com relação aos tipos de solos encontrados na área quanto a espacialização das áreas susceptíveis aos escorregamentos.

Os valores referentes ao ensaio de cisalhamento direto variaram de $28,9^{\circ}$ a $37,77^{\circ}$ para o ângulo de atrito, e entre 2,9 e $14,6 \mathrm{kPa}$ para coesão. Os valores calculados com base no SPT, por sua vez, variaram de $30,61^{\circ}$ a $32,39^{\circ}$ para o ângulo de atrito interno, enquanto para a coesão, os dados variaram de 2,87 a $9,08 \mathrm{kPa}$. A menor variação para esses parâmetros está entre os valores obtidos analiticamente para o ângulo de atrito baseado no SPT, além de que, na média, o valor também é menor. Por este motivo os valores utilizados no cálculo do FS fundamentaram-se nos valores obtidos pelo segundo método descrito (ângulo de atrito, coesão e profundidade).
Conforme apresentado, pode-se dizer que a análise realizada para obtenção de valores relativos a ângulo de atrito e coesão baseados nos valores constantes em boletins de sondagem SPT são satisfatórios para aplicação em mapas de susceptibilidade. Embora menores que os valores resultantes de ensaios de cisalhamento direto, os valores baseados em SPT podem ser utilizados sem prejuízo ao resultado final obtido.

A obtenção dos valores, principalmente ângulo de atrito e coesão por meio do ensaio de cisalhamento direto mostrou-se dispendioso com relação ao investimento necessário para coleta e ensaios laboratoriais, bem como ao tempo necessário para a obtenção dos resultados. Além de dispendioso, ainda há o inconveniente de o ensaio de cisalhamento direto representar apenas o comportamento do solo em pequena escala. Como é necessário a utilização de tecnologia avançada, software e equipamento utilizados no ensaio também podem exercer influências negativas, gerando resultados que podem não condizer com a realidade.

Considerando-se que as sondagens SPT representam uma das investigações mais difundidas e utilizadas no Brasil, uma base de dados de resultados do uso dessa técnica poderia ser utilizada para obtenção de mapas de susceptibilidade a escorregamentos, assim como também poderia ser ampliada de maneira extensiva. Além disso, é possível reduzir custos com os estudos de instabilidade de vertentes por meio da utilização de uma grande quantidade de informação já disponível, podendo ser aplicado em áreas que ainda não possuem estudos de estabilidade, mas que carecem deste tipo de pesquisa.

O presente estudo obteve êxito ao demonstrar a viabilidade da utilização de técnicas alternativas e métodos indiretos para obtenção de mapas previsionais de condições futuras e que podem ser utilizados em diversas áreas.

De qualquer modo, pesquisas futuras devem ser realizadas, nos mais diversos tipos de solo, para que o 
método possa ser difundido e aplicado com o menor custo possível. Isto poderá possibilitar o uso de pesquisas como instrumento de gestão, ou seja, verdadeiramente, como um trabalho de prevenção, e não somente de remediação dos locais afetados por movimentos de massa.

\section{Referências bibliográficas}

ABNT - Associação Brasileira de Normas Técnicas. 2001. NBR 6484 - Execução de sondagens de simples reconhecimento dos solos. Rio de Janeiro.

ABNT - Associação Brasileira de Normas Técnicas. 1986. NBR 9604 - Abertura de poço e trincheira de inspeção em solo, com retirada de amostras deformadas e indeformadas. Rio de Janeiro.

AMARAL JUNIOR, A. F. 2007. Mapeamento geotécnico aplica a análise de processos de movimentos de massa gravitacionais: Costa Verde-RJ, Escala 1:10.000. Dissertação de mestrado. Escola de Engenharia de São Carlos. Universidade de São Paulo.

BORCHARDT, N. 2005. Diagnóstico geológico-geotécnico na estabilidade de vertentes do alto e médio curso da bacia do Rio Sagrado, PR. Dissertação de mestrado. Pós-Graduação em Geologia, Departamento de Geologia, Universidade Federal do Paraná.

CINTRA, J. C. A.; AOKI, N.; TSUHA, C. H.; GIACHETI, H. 2013. Fundações: ensaios estáticos e dinâmicos. São Paulo: Oficina de Textos.

BRAJA, M. D. 2013. Fundamentos de engenharia geotécnica. Traduação All Tasks: revisão técnico Pérsio Leister de Almeida Barros. São Paulo: Cengage Learning.

ESRI, Desktop. 2011. Release 10. Redlands. CA: Environmental Systems Research Institute.

FERREIRA, F. S. 2013. Análise da influência das prorpiedades físicas do solo na deflagração dos escorregamentos translacionais rasos na Serra do Mar (SP). Dissertação de Mestrado. Programa de pós-graduação em Geografia Física da Faculdade de Filosofia, Letras e Ciências Humanas da Universidade de São Paulo. São Paulo, 112p.

FIORI, A. P; CARMIGNANI, L. 2009. Fundamentos de mecânica dos solos e das rochas. Curitiba: Ed. UFPR, 2009. 604p.

GUIDICINI, G.; NIEBLE, C M.1983. Estabilidade de taludes naturais e de escavação. São Paulo, Edgard Blucher LTDA. 196p.

HATANAKA, M.; UCHIDA, A. 1996. Soils and Foundations. Japanese Geotechical Society. Vol. 36, n. 4, 1-9.

KOZCIAK, S. 2005. Análise determinística da estabilidade de vertentes na bacia do Rio Marumbi - Serra do Mar - Paraná. Tese de doutorado. Programa de Pós-Graduação em Geologia. Departamento de Geologia, Universidade Federal do Paraná, $151 \mathrm{p}$.

LIAO, S. S. C.; WITHMAN, R. V. 1986. Overburden correction factors for SPT in sand.. In Journal of Geotechnical Engineering, ASCE, vol. 112, n. 3, pp $373-377$

PINTO, Carlos de S. 2000. Curso básico de Mecânica dos solos em 16 aulas. Oficina de Textos, São Paulo, 247p.

SCHNAID, f. 2000. Ensaios de campo e suas aplicações à engenharia de fundações. São Paulo. Oficina de Textos, 2000. $189 \mathrm{p}$.

SILVA, E. L.; GOMES, R. A.; GUIMARÃES, R. F.; CARVALHO JÚNIOR, O. A. 2013. Emprego de modelo de susceptibilidade a escorregamentos rasos para gestão de riscos de desastres no município de Vitória-ES. Sociedade \& Natureza, v. 25, p. 119132

SILVEIRA, C. T.; OKA-FIORI, C.; SANTOS, L.J.C.; SIRTOLI, A E.; DA SILVA, C. R. 2012. Pedometria apoiada em atributos topográficos com operações de tabulação cruzada por álgebra de mapas. In: Revista Brasileira de Geomorfologia. v. 13, no 2, p. 125-137.

STROUD, M. A. 1989. The Standard Penetration Test - its application and interpretation. Proc. I.C.E. Conf. on Penetration Testing, Inglaterra, Londres. Thomas Telford, 1989.

WOLLE, C. M.; C. S. CARVALHO. 1989. Deslizamento em encostas na Serra do Mar-Brasil. Solos e Rochas: p. 27-36.
Manuscrito ID 38906

Submetido em dezembro de 2014

Aceito em agosto de 2017 